\title{
ON THE DESIGN OF AN OPTIMUM ACTIVE MASS-SPRING-INVERTED PENDULUM DYNAMIC VIBRATION ABSORBER FOR THE INVERTED PENDULUM TYPE STRUCTURE
}

\author{
Nguyen Chi Sang, Nguyen Cao Thang \\ National Research Institute of Mechanical Engineering, Hanoi, Vietnam
}

\begin{abstract}
A Dynamic Vibration Absorber (DVA) is appropriate equipment for vibration control in many kinds of engineering. In general, there are two main types of DVAs: the passive DVAs and the active DVAs. The paper presents a design of an active massspring-inverted pendulum DVA for the inverted pendulum type structure in case the external force is white noise process. The design is based on the optimum passive DVA as carried out in [4] and apply the optimum control force by minimizing the performance index. Numerical simulation which is done for an inverted pendulum structure in the ocean in three cases without DVA, with passive DVA, with active DVA shows that the active DVA is better than the passive one.
\end{abstract}

\section{INTRODUCTION}

The applications of the passive Dynamic Vibration Absorber (pDVA) as an addition tool for primary system excited by harmonic or narrow-band excitations had the advantage of low cost and reliability $[1,2]$. However, its effectiveness is limited because it can only store and dissipation system's energy; therefore, the active DVA (aDVA) which can apply control force into system was investigated [3]. The passive mass-spring-pendulum type pDVA for a stable inverted pendulum type structure was carried out in [4] with the optimum parameters of the pDVA were obtained by minimizing ratio of mean squares of displacement of primary system with/without pDVA. In this paper a design of the active mass-spring-inverted pendulum type aDVA for the stable inverted pendulum type structure is investigated in case the excitation force is white noise process. The design is based on the method used to find optimum pDVA as described in [4] and apply the optimum control force by minimizing the performance index of the system. The performance index is presented as a function of the primary system's responses and the control force with their non negative weighting constants. The ratio of mean squares of displacement of primary system with/without aDVA is calculated and compared with the ratio of mean squares of displacement of the primary system with/without pDVA. Numerical simulation is done in an example of the articulated tower in the ocean. The results show that the aDVA has better performance than the pDVA has. 


\section{EQUATION OF MOTION}

As shown in Fig. 1, the inverted pendulum structures have a concentrated mass $m$ at the top and one degree of freedom $\theta$ about z-axis. The concentrated mass is supported by a beam. We consider the case where the beam bending stiffness is large enough so that the beam can be modeled as a rigid rod which has the length of $l$ and the uniform mass per unit length of $\rho$. The damping of the pendulum is neglected. To keep the structure have a stable upright position, a restoring moment is produced by a torsion spring with the spring constant of $K$. The dynamic absorber has mass-spring-pendulum type with the mass of $m_{d}$, the length of $l_{d}$, the spring constant of $k_{d}$, and the damping constant of $c_{d}$. Denoting the angle variation of the dynamic absorber with respect to the main structure is $\theta_{d}$.

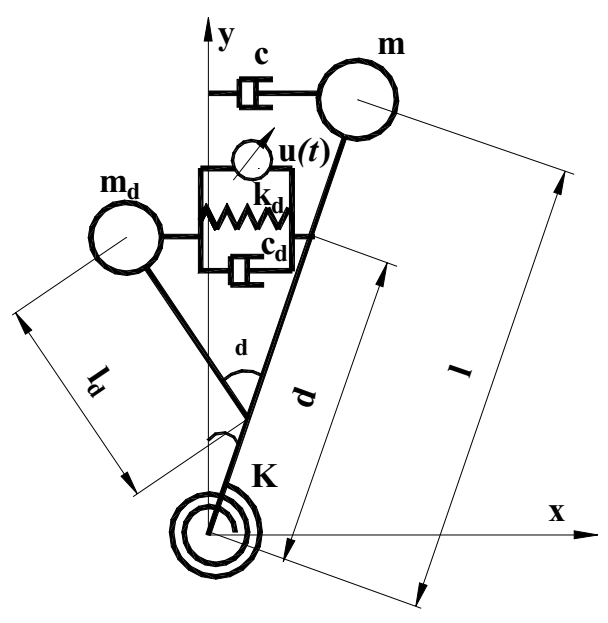

Fig. 1. The inverted pendulum type structure with the active DVA (aDVA)

When the structures is excited by the external force $p(t)$, and control force $u(t)$ the motions equations of the inverted pendulum-aDVA are derived using Lagrange's equations:

$$
\begin{aligned}
& {\left[\begin{array}{cc}
m l^{2}+\frac{\rho l^{3}}{3}+m_{d}\left(d+l_{d}\right)^{2} & -m_{d} d l_{d}-m_{d} l_{d}^{2} \\
-m_{d} d l_{d}-m_{d} l_{d}^{2} & m_{d} l_{d}^{2}
\end{array}\right]\left[\begin{array}{c}
\ddot{\theta} \\
\ddot{\theta}_{d}
\end{array}\right]+\left[\begin{array}{cc}
c l_{2} & 0 \\
0 & c_{d} l_{d}^{2}
\end{array}\right]\left[\begin{array}{c}
\dot{\theta} \\
\dot{\theta}_{d}
\end{array}\right]} \\
& +\left[\begin{array}{cc}
K-m g l-\frac{\rho g l^{2}}{2}-m_{d} g\left(d+l_{d}\right) & m_{d} g l_{d} \\
m_{d} g l_{d} & k_{d} l_{d}^{2}-m_{d} g l_{d}
\end{array}\right]\left[\begin{array}{c}
\theta \\
\theta_{d}
\end{array}\right]=\left[\begin{array}{c}
l p(t)+\left(d+l_{d}\right) u(t) \\
l_{d} u(t)
\end{array}\right]
\end{aligned}
$$


Introducing the dimensionless parameters:

$$
\begin{aligned}
& \mu=\frac{m_{d}}{m+\rho l / 3}, \quad \gamma=\frac{d+l_{d}}{l}, \\
& \omega_{s}=\sqrt{\frac{K}{m l^{2}+\rho l^{3} / 3}-\frac{(6 m+3 \rho l) g}{6 m l+2 \rho l^{2}}}=\sqrt{\frac{6 K-g l(6 m+3 \rho l)}{2 l^{2}(3 m+\rho l)}} \\
& \omega_{d}=\sqrt{\frac{k_{d}}{m_{d}}-\frac{g}{l_{d}}}, \quad \xi_{d}=\frac{c_{d}}{2 m_{d} \omega_{d}}, \quad \alpha=\frac{\omega_{d}}{\omega_{s}}, \quad \eta=\frac{g}{\omega_{s}^{2} l}, \quad \xi=\frac{c}{2(m+\rho l / 3) \omega_{s}}
\end{aligned}
$$

where: $\mu$ is the mass ratio, $\gamma$ specifies the position of the aDVA, $\omega_{s}$ is the natural frequency of the structure, $\omega_{d}$ and $\xi$ are the natural frequency and the damping ratio of aDVA, respectively, $\alpha$ is the natural frequency ratio, $\eta$ specifies the distribution of mass of the structure. Denoting

$$
q=l \theta, \quad q_{d}=-l_{d} \theta_{d}
$$

Therefore, equation (1) reduces to the non-dimensional form

$$
M \ddot{X}+C \dot{X}+K X=B p(t)+E u(t),
$$

where,

$$
\begin{aligned}
& \mathrm{M}=\left[\begin{array}{cc}
1+\mu \gamma^{2} & \mu \gamma \\
\gamma & 1
\end{array}\right] ; \mathrm{C}=\omega_{s}\left[\begin{array}{cc}
2 \xi & 0 \\
0 & 2 \xi_{d} \alpha
\end{array}\right] ; \mathrm{K}=\omega_{s}^{2}\left[\begin{array}{cc}
1-\mu \gamma \eta & -\mu \eta \\
-\eta & \alpha^{2}
\end{array}\right] \\
& \mathrm{B}=\left[\begin{array}{c}
\frac{3}{3 m+\rho l} \\
0
\end{array}\right] ; \mathrm{E}=\left[\begin{array}{c}
\frac{3 \gamma}{3 m+\rho l} \\
-\frac{1}{m_{d}}
\end{array}\right], \mathrm{X}=\left[q, q_{d}\right]^{T}
\end{aligned}
$$

$p(t)$ is excitation force of the environment such as wave, storm, and $u(t)$ is control force of the aDVA. In case of design pDVA, the $u(t)$ is absented. The stability condition $(c \geq 0)$ for the system is given in [4] as follows.

$$
(1-\mu \gamma \eta) \alpha^{2}-\mu \eta^{2}>0 \text {. }
$$

The stability condition (6) limits values of the system parameters. For example, if the weight of the absorber is too high ( $\mu$ too large), the structure-aDVA system will be unstable.

\section{OPTIMAL CONTROL FORCE FOR ADVA}

In case the excitation is defined as white noise process

$$
p(t)=\sigma \dot{\xi}(t)
$$

where: $\sigma$ is positive constant and is the intensity of white noise process; $\dot{\xi}(t)$ is white noise process with unit spectral density.

The equation (4) can be rewritten in state space equation as follows.

$$
\dot{Z}(t)=A Z(t)+D p(t)+H u(t),
$$

where:

$$
Z=[X, \dot{X}]^{T} \text { is the state space vector of the system; }
$$




$$
\begin{gathered}
A=\left[\begin{array}{cc}
0 & I \\
-M^{-1} K & -M^{-1} C
\end{array}\right]_{4 \times 4}, I \text { is unit matrix order } 2 \times 2 ; \\
D=\left[\begin{array}{l}
0 \\
M^{-1} B
\end{array}\right]_{4 \times 1} \\
H=\left[\begin{array}{c}
0 \\
M^{-1} E
\end{array}\right]_{4 \times 1} .
\end{gathered}
$$

The criteria of select parameters for the feedback control force is based on the minimization of performance index

$$
J=\frac{1}{2}\left\langle\int_{0}^{T}\left[Z^{T}(t) Q Z(t)+\beta u^{2}(t)\right] d t\right\rangle \rightarrow \min _{u(t)}
$$

where: weight matrix $Q$ is non negative matrix prior to system response, $\beta$ is positive weight constant prior to control force.

Minimizing the performance index (10) will lead to the algebra Riccati equation

$$
W A+A^{T} W-\frac{1}{\beta} W H H^{T} W+Q=0,
$$

where: $W$ is a Riccati matrix.

And, the feedback control force $u(t)$ is a function of state space variables of system:

$$
u(t)=-\frac{1}{\beta} H^{T} W Z(t)=-G Z(t),
$$

where: $G=-\frac{1}{\beta} H^{T} W$ is a gain matrix.

The ratio $R_{a}$ of mean square of displacement of the primary system with aDVA/without aDVA is defined as follows.

$$
R_{a}=\frac{\left\langle{ }^{a} x_{1}^{2}\right\rangle}{\left\langle x_{10}^{2}\right\rangle}
$$

where:

$-\langle\ldots\rangle$ is the mathematical expectation.

- $\left\langle{ }^{a} x_{1}^{2}\right\rangle,\left\langle x_{10}^{2}\right\rangle$ are the mean squares of primary pendulum's displacement in cases with aDVA and without aDVA, respectively.

\section{NUMERICAL SIMULATION}

One of the examples of inverted pendulum is the articulated tower in the ocean. Consider the numerical data: tower length $l=400 \mathrm{~m}$, tower uniform mass per unit length $\rho=20 \times 10^{3} \mathrm{~kg} / \mathrm{m}$, end mass $m=2.5 \times 10^{5} \mathrm{~kg}$, the natural frequency of the tower: $\omega_{s}=0.44$ $\mathrm{rad} / \mathrm{s}$, damping ratio of inverted pendulum is $\xi=3 \%$, the intensity of white noise process is $\sigma=10^{10}$. Absorber's mass $\mathrm{m}_{d}$ is about $5.8 \times 10^{4} \mathrm{~kg}(\mu=2 \%)$ the length of the absorber $l_{d}$ is fixed at the value of $15 \mathrm{~m}$ and be inverted as shown in Fig. 1, the absorber is located at 
the distance $d=200 \mathrm{~m}$ from the seabed. Therefore, $\gamma=0.5375, \eta=0.1266$, the optimum parameters of the passive absorber was obtained as described in [4] as follows.

$$
\alpha_{\text {opt }}=0.9651, \quad \xi_{\text {opt }}=0.0475
$$

Define ratio of the mean square of primary pendulum's response with/without pDVA

$$
R_{p}=\frac{\left\langle{ }^{p} x_{1}^{2}\right\rangle}{\left\langle x_{10}^{2}\right\rangle}=0.64
$$

where,

- $\left\langle{ }^{p} x_{1}^{2}\right\rangle,\left\langle x_{10}^{2}\right\rangle$ are the mean squares of primary pendulum's response with pDVA and without pDVA, respectively.

These parameters satisfy the stability criterion (6) as shown below.

$$
(1-\mu \gamma \eta) \mu \alpha^{2}-\mu^{2} \eta^{2}=0.018>0
$$

The physical parameters of pDVA are as follows.

$$
\begin{aligned}
& k_{d}=m_{d}\left(\alpha_{o p t}^{2} \omega_{s}^{2}+\frac{g}{l_{d}}\right)=48,4(k N / m) \\
& c_{d}=2 \xi_{\text {opt }} m_{d} \alpha_{\text {opt }} \omega_{s}=2,362(k N s / m)
\end{aligned}
$$

In order to increase the performance of the pDVA, one can apply the optimum control force to the primary system from the aDVA. The values of the weight matrix $\mathrm{Q}$ and weight constant $\beta$ can be selected as follows in case minimizing the displacement of the primary system.

$$
Q=\left[\begin{array}{llll}
1 & 0 & 0 & 0 \\
0 & 0 & 0 & 0 \\
0 & 0 & 0 & 0 \\
0 & 0 & 0 & 0
\end{array}\right] ; \quad \beta=10^{-10}
$$

With above selected parameters, one can solve algebra Riccati equation (11) to find the gain matrix $G$ of the optimum control force $u(t)=-G Z(t)$ as follows.

$$
G=[1.73390 .00881 .5663-0.0795] * 10^{4} .
$$

The ratio $R_{a}$ which shows effectiveness of aDVA can be calculated and compared with $R_{p}$ which shows effectiveness of pDVA:

$$
R_{a}=0.15<R_{p}=0.64<1
$$

The effectiveness of DVAs can be seen in Fig. 2 and 3. The aDVA has better performance than the pDVA has. The vibration of the primary system with aDVA reduces one-third of it in case without DVA, sometimes. 


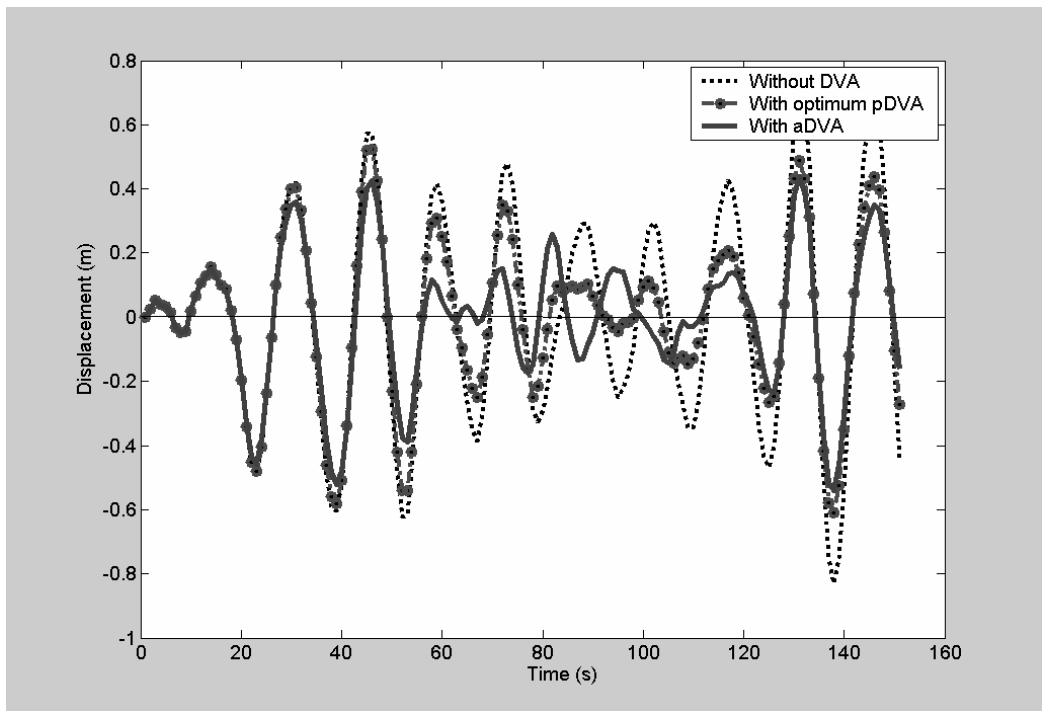

Fig. 2. Displacements of the tower without DVA, with passive DVA, with active DVA

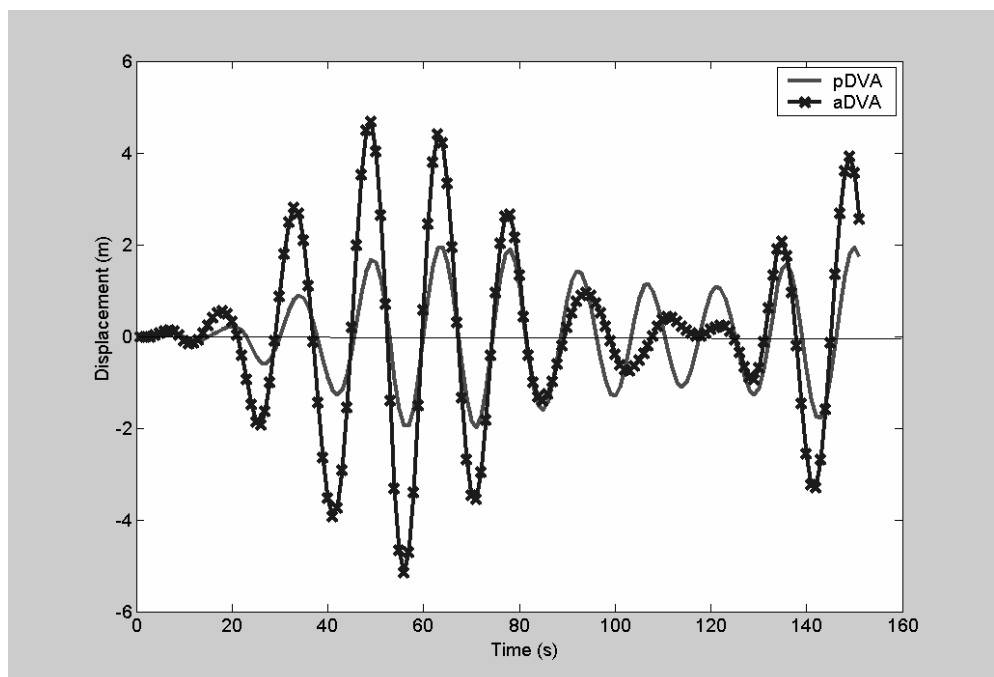

Fig. 3. Displacement of the passive DVA and active DVA

\section{CONCLUSION}

The Dynamic Vibration Absorber is appropriate equipment for vibration control in many kinds of engineering. In this paper, the design of the active DVA is investigated in case the external excitation is white noise process. The design is based on method used to find the optimum pDVA as described in [4] and apply the optimum control force 
by minimizing the performance index of system. The ratio of mean squares of displacement of primary system with/without aDVA is less than the one of the primary system with/without pDVA. It is shown that the aDVA has better performance than the pDVA has by the simulation.

\section{REFERENCES}

[1] J. P. Den Hartog. Mechanical Vibration (4th Edition ed.), McGraw-Hill, 87-106, (1956).

[2] R. G. Jacquot, D. Hoppe, Optimal random vibration absorbers. Journal of Engineering Mechanics Division, American Society of Civil Engineers 99 , 612-616, 1973.

[3] W. Zuk, The past and future of active structural control systems, In Leipholz H E (ed.), Structural control North Holland, Amsterdam, pp 779-794, 1980.

[4] N. D. Anh, H. Matsuhisa, N. C. Sang, N. C. Thang, On the control of an inverted pendulum type structure using mass-spring-pendulum dynamic vibration absorber, The fifth Asian Symposium on Electronics Applied in Mechanics in Hanoi, 2005.

[5] Nguyen Chi Sang, Research and design Tuned Mass Damper (TMD) for multi degree of freedom systems, PhD. Thesis in Mechanics, 2004.

Received October 20, 2008

\section{THIẾT KẾ BỘ HẤP THỤ DAO ĐộNG TÍCH CỰC VÀ TỐI ƯU DẠNG CON LĂC NGƯợC KHỐI LƯợNG O LÒ XO CHO KẾT CẤU DẠNG CON LẮC NGƯợC}

Bộ hấp thụ dao động (DVA) là một thiết bị thích hợp dùng để điều khiển dao động trong nhiều loại máy móc. Nói chung, có hai loại DVA: loại thụ động và loại tích cực. Bài báo này trình bày thiết kế DVA tích cực và tối ưu dạng con lắc ngược khối lượng - lò xo cho kết cấu dạng con lắc ngược trong trường hợp ngoại lực là quá trình ồn trắng. Việc thiết kế này dựa trên một bộ hấp thụ dao động thụ động tối ưu đã tìm ra trước ở [4] và thêm vào đó một lực điều khiển tối ưu bằng việc cực tiểu hóa chỉ số chất lượng. Mô phỏng máy tính đã được thực hiện cho một kết cấu dạng con lắc ngược ở ngoài biển trong ba trường hợp: không gắn DVA, có gắn DVA thụ động, có gắn DVA tích cực cho ta thấy bộ hấp thụ dao động kiểu tích cực có hiệu quả tốt hơn so với kiểu thụ động. 